Article

\title{
Carbon Emissions Abatement Cost in China: Provincial Panel Data Analysis
}

\section{Jianjun Wang ${ }^{1}{ }^{1}, \mathrm{Li} \mathrm{Li}^{2}$, Fan Zhang ${ }^{1}$ and Qiannan Xu ${ }^{1}$}

1 School of Economics and Management, North China Electric Power University, Hui Long Guan, Chang Ping District, Beijing 102206, China; E-Mails: jdydhappy@163.com (F.Z.); qiannanv2008@126.com (Q.X.)

2 School of Economics and Management, Beijing Information Science \& Technology University, Beijing 100195, China; E-Mail: lilinw2001@126.com

* Author to whom correspondence should be addressed; E-Mail: wangjianjun@ncepu.edu.cn or wangjianjunhd@126.com; Tel.:+86-10-6177-3123; Fax:+86-10-8079-6904.

Received: 10 January 2014; in revised form: 14 April 2014 / Accepted: 16 April 2014 /

Published: 2 May 2014

\begin{abstract}
This paper employs the quadratic directional output distance function to derive shadow prices of China's aggregate carbon emissions at the province level between 1997 and 2010. The empirical results indicate that the national weighted average shadow price presents an "N-shape" curve across the sample period, experiencing the initial phase of growth followed by a phase of deterioration, and then a further increase. This change trend implies that the cost of carbon emissions reduction is increasing. In addition, the shadow price varies significantly across provinces, which means that China should uphold the principal of "common but differentiated responsibilities" in regional carbon emissions reduction. Generally, the shadow price of the east provinces with high economic development is markedly higher than that of the west provinces with low economic development. The OLS regression results indicate that the shadow price positively connected with the regional economic development levels. Moreover, an inflection point exists in the relation curve between the shadow price and GDP per capita, that is, the increase rate of the shadow price becomes small when the GDP per capita is less than 18.1 thousand Yuan, while it becomes large when the GDP per capita surpasses 18.1 thousand Yuan. With the economic growth, the cost of carbon emissions reduction would be significantly increased. The empirical results can provide more insight for policymakers.
\end{abstract}


Keywords: carbon emissions; shadow prices; directional output distance function

\section{Introduction}

China's significant economic growth simultaneously results in the rapid rise in energy consumption and carbon emissions. China has been the largest energy-related $\mathrm{CO}_{2}$ emitter in the world since 2007 and the largest energy consumer since 2010. According to the data issued by BP [1], China's energy consumption was higher than that of the United States by 150 million tons of oil equivalent in 2010. China features rich coal in energy composition. As illustrated in Figure 1, coal always accounts for about $70 \%$ of total primary energy in China. In order to restructure primary energy, China issued the development program of shale gas in 2012, in which the production of shale gas will be 6.5 billion cubic meters in 2015 and $60-100$ billion cubic meters in 2020. Although shale gas is considered the most possible alternative to effectively substitute for the fossil energy in the future, the substitution effect is trivial since the output of shale gas is very low compared with the total energy consumption in China. For example, China totally consumed about 3.25 billion ton of coal equivalent in 2010, of which coal accounted for about $68 \%$ (about 2.21 billion ton of coal equivalent). The shale gas of 6.5 billion cubic meters in 2015 and 60-100 billion cubic meters in 2020 can only substitute for about 5 million ton of coal equivalent in 2015 and about 46-77 million ton of coal equivalent in 2020, respectively. Therefore, the high-carbon energy of coal will still be the crucial primary energy in China in the foreseeable future. Although the difficulty of carbon emissions abatement is huge for the developing country of China, China government has committed to reducing carbon intensity by $40 \%-45 \%$ by the year 2020 , compared with 2005 levels. In order to fulfill its ambitious goal of carbon reductions, China must take the national situation into account to formulate policies. It is worth noting that China features significantly different mechanism of economic growth across regions. Therefore, the carbon emissions abatement cost may markedly vary across regions, which means that China should uphold "common but differentiated responsibilities" across regions. Therefore, this paper measures provincial shadow prices of $\mathrm{CO}_{2}$ emissions and provides policy suggestions to policymakers.

Figure 1. Ratio of energy consumption in China, 2010.

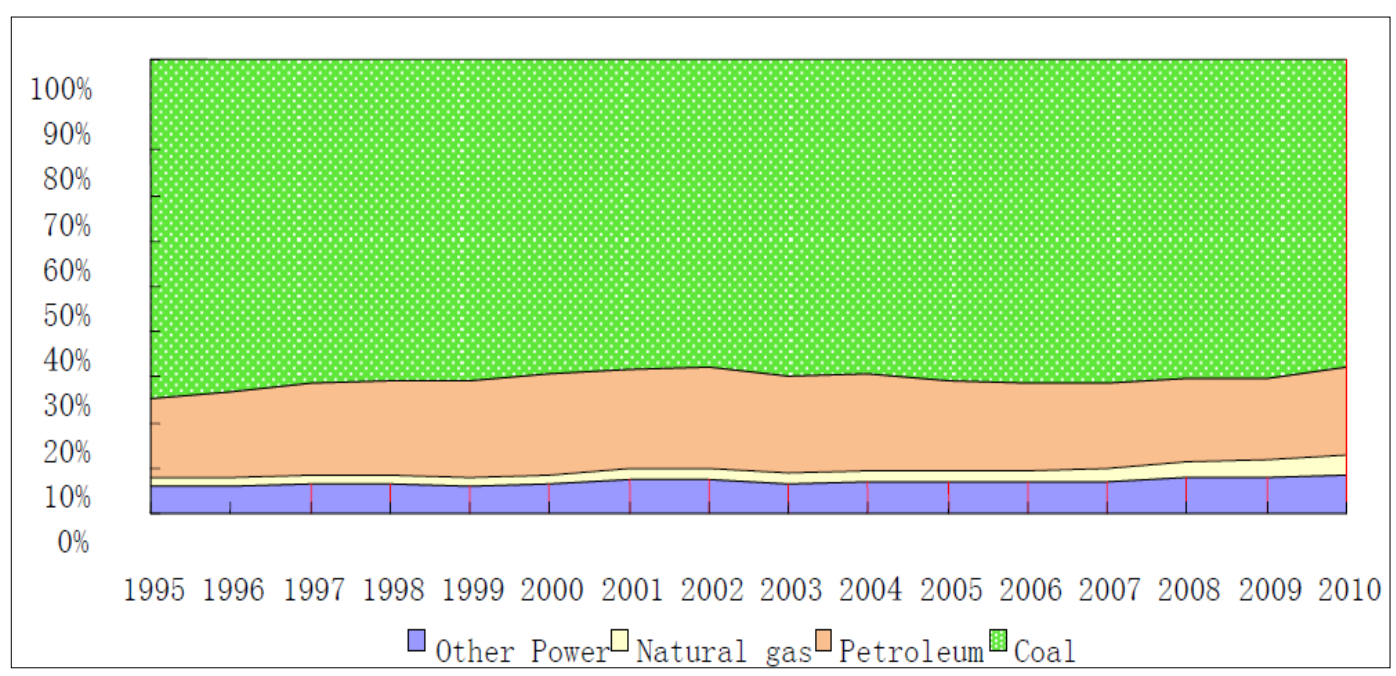


Since undesirable outputs like carbon dioxide cannot be reasonably priced in accordance with general commodities, the carbon emissions abatement cost have not been included in the accounting system in China. It is not beneficial to the regulation of factories' discharges or the implementation of emission-cutting policies. The shadow price, or the marginal abatement cost of undesirable outputs, can be interpreted as the opportunity cost of reducing an additional unit of undesirable output in terms of forgoing desirable output. Therefore, it is introduced to price the undesirable outputs properly. To estimate the shadow price, cost function and distance function are the two widely used methods. Cost function can provide information about the relation between the marginal abatement cost of pollutants and actual emission levels under the assumption concerning cost minimization. For example, Gollop and Roberts [2] estimate the shadow price of $\mathrm{SO}_{2}$ in fossil-fueled power plants of the United States of America by employing cost function. Distance function, originally introduced by Shephard [3], requires neither the hypothesis concerning cost-minimizing behavior nor information on input prices or regulatory constraints. It therefore has been widely employed to estimate shadow price of undesirable outputs. Generally, the distance function can be estimated in two ways, i.e., the nonparametric data envelopment analysis (DEA) approach and the parametric approach.

The nonparametric DEA estimation is based on the construction of a piecewise linear combination of all observed outputs and inputs, which relies on mathematical programming for the computation of efficiency scores. For example, Lee use this method to derive shadow prices of $\mathrm{SO}_{2}, \mathrm{NO}_{x}$ and total suspend particulates for Korean coal-burning and oil-burning plants in 1990-1995 [4]. Kaneko is taking the thermal power sector of China as a case, find that the marginal abatement cost of $\mathrm{SO}_{2}$ in 2006 significantly had declined by approximately half since 2003 [5].

In the line of the parametric approach, Shephard output/input distance function is usually parameterized by the transcendental logarithmic functional form. Färe originally employ Shephard/translog method to estimate shadow prices for undesirable outputs of 30 paper and pulp mills operating in Michigan and Wisconsin [6]. Since then, extensive researchers have used methods of this line to investigate shadow price of undesirable outputs. For example, Lee estimates shadow prices of $\mathrm{SO}_{2}$ with data from 51 coal-fired USA power units operating between 1977 and 1986, and indicates that the weighted average shadow price is $\$ 0.076$ per pound in constant 1976 , which is lower than the result without considering the substitutability of capital for sulfur [7]. Hu find the marginal abatement cost of $\mathrm{SO}_{2}$ in west areas of China is the highest and that of central areas is the lowest [8]. Similar frameworks to characterize the marginal abatement cost of pollutants are conducted by Hailu [9] and Murty [10].

Recently, the directional output distance function is increasingly influential in estimating shadow price of pollutants [11]. It appeals to the environmental policies because of allowing the expansion of desirable outputs and the reduction of undesirable outputs simultaneously. Correspondingly, the quadratic functional form is usually employed to parameterize the directional output distance function, because the former allows restrictions required by the translation property and experts in the second-order approximation of unknown distance functions. Based on the directional/quadratic method, Färe investigate fossil-fueled utilities in the USA during 1993-1997 and indicate that shadow prices of $\mathrm{SO}_{2}$ vary from $\$ 1117 /$ ton to $\$ 1974 /$ ton [12]. Färe derive shadow prices of polluting outputs for the USA agricultural sector during 1960-1996 [13]. Vardanyan and Noh choose a panel of observations from the USA electric utility industry to estimate shadow prices of $\mathrm{SO}_{2}$ [14]. Matsushita and Yamane derive shadow prices of $\mathrm{CO}_{2}$ and low-level waste in the case of the electric power sector in Japan [15]. 
A few studies estimated shadow price of carbon emissions at China's provincial levels. Using the nonparametric DEA method, Wang estimated shadow price of $\mathrm{CO}_{2}$ for China's 28 provinces in 2007 [16]. Choi employed the slacks-based DEA model to estimate the marginal abatement costs of $\mathrm{CO}_{2}$ emissions for China's 30 provinces during 2001-2010 [17]. In addition, some existing studies on shadow price of China's $\mathrm{CO}_{2}$ emissions adopt the data arranged by sectors. For example, Yuan measured shadow prices of $\mathrm{CO}_{2}$ emissions by using data from China's 24 industrial sectors in 2004 and 2008 [18]. Lee and Zhang chose the parametrized Shephard input distance function to estimate shadow price of $\mathrm{CO}_{2}$ emissions for 30 Chinese manufacturing industries in 2009 [19].

Unlike the above studies, this paper conduct a directional output distance function to derives shadow price of $\mathrm{CO}_{2}$ emissions, because directional output distance function allows the expansion of good outputs and contraction of bad outputs simultaneously. In addition, the parametric approach with a specific functional form has the advantage of providing an estimated parametric representation of the true production technology that is everywhere differentiable. The very feature implies shadow price can be defined through the assumption that the observed price of one desirable output equals its shadow price [20]. We extend the size of provincial data to include a wider range of time span. In short, this paper attempts to employ a parametrized directional output distance function to estimate shadow prices of China provincial $\mathrm{CO}_{2}$ emissions from 1997 to 2010. The empirical results are expected to present some valuable policy implications for China to reduce carbon emissions.

The remainder of this paper is organized as follows. Section 2 introduces the directional output distance function and derives shadow price model. Section 3 presents the procedure to estimate shadow prices of $\mathrm{CO}_{2}$ emissions, discusses empirical results and provides some policy implications in emissions reductions. Section 4 concludes this paper.

\section{Methodology}

A common feature of Shephard distance functions is that they assume the maximal possible proportional expansions onto the boundary of $P(x)$ about the observed desirable and undesirable outputs. However, the directional output distance function can expand desirable outputs and contract undesirable outputs simultaneously by choosing a particular direction vector.

\subsection{The Directional Output Distance Function}

In fact, the directional output distance function is a functional representation of the production technology. The production units employ inputs $(x)$ to produce good (desirable) outputs $(y)$ and bad outputs $(b)$. The production technology is expressed as $P(x)=\{(y, b): x$ can produce $(y, b)\}$. In order to specify the production technology involving desirable and bad outputs which are jointly produced, some of the assumptions are imposed. Specifically, $P(x)$ is a compact set with $P(0)=\{0,0\}$ and inputs are strongly or freely disposable. Allowing for production of both good and bad outputs, we assume that good and bad outputs are weakly disposable, which means that any proportional contraction of good and bad outputs together is feasible. A decrease in bad outputs inevitably causes a reduction in good outputs with given inputs, which corroborates the idea that it is costly to reduce bad outputs. The final assumption is the null-jointness about desirable outputs and undesirable outputs, which means if no bad outputs are produced, it is technically or economically impossible to produce any good outputs, or good outputs are consequently accompanied by bad outputs. 
Suppose $g=\left(g_{y}, g_{b}\right) \neq 0$ is the direction vector, and the directional output distance function can be described as

$$
\overrightarrow{D_{0}}\left(x, y, b ; g_{y}, g_{b}\right)=\max \left\{\beta:\left(y+\beta g_{y}, b-\beta g_{b}\right) \in P(x)\right\}
$$

The function denotes that the simultaneous maximum reduction in bad outputs and expansion in good outputs are feasible in a given production technology. As illustrated in Figure 2, the directional output distance function can expand $y$ and contract $b$ along the direction of $g$ until it reaches the boundary of $P(x)$ at the point $\left(b-\beta^{*} g_{b}, y+\beta^{*} g_{y}\right)$, where, $\beta^{*}=\vec{D}_{0}(\mathrm{x}, y, b ; g)$. The shadow price ratio for the observation unit with coordinates $(b, y)$ is provided by the slope of the tangent line estimated on the frontier of $P(x)$.

Figure 2. The directional output distance function.

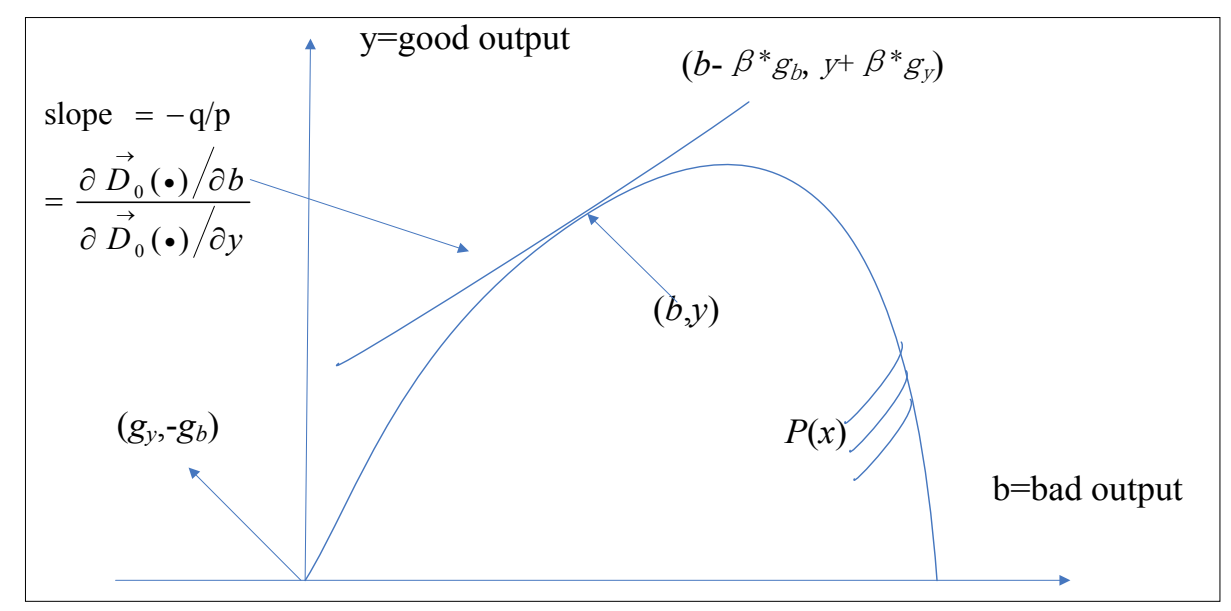

The distance function takes the value of zero for technically efficient outputs on the boundary of $P(x)$, while positive values suggest inefficient outputs inside the boundary. Corresponding to homogeneity of the standard Shephard output distance function, the directional distance function has the following translation property:

$$
\overrightarrow{D_{0}}\left(x, y+\alpha g_{y}, b-\alpha g_{b} ; g\right)=\vec{D}_{0}(x, y, b ; g)-\alpha,
$$

If the directional vector is $g=(y,-b)$, the relation between the directional distance function and Shephard output distance function is established as follows:

$$
\vec{D}_{0}(x, y, b ; y,-b)=\frac{1}{D_{0}(x, y, b)}-1
$$

where $D_{0}(x, y, b)=\min \{\lambda:(y / \lambda, b / \lambda) \in P(x)\}$,

The directional output distance function is a generalization of the Shephard output distance function, or the latter is a special case of the former. 


\subsection{The Shadow Price Model}

The undesirable outputs are generally non-marketable, whose values can be deduced from the relation between the directional distance function and the revenue function. Let $p=\left(p_{1}, \ldots, p_{M}\right)$ represents the price vector of good outputs, and let $q=\left(q_{1}, \ldots, q_{J}\right)$ represents the price vector of bad outputs, and also $l=\left(l_{1}, \ldots, l_{N}\right)$ is the price vector of inputs. The maximal revenue function is defined as

$$
R(l, p, q)=\max _{x, y, b}\{p y-q b-l x:(y, b) \in P(x)\},
$$

Obviously, Equation (4) shows that the bad outputs have a negative effect on the revenue. Contraction in bad outputs will bring economic loss, to some degree.

The generating units $(y, b)$ either lie on the production frontier, or inside the frontier, i.e., $\vec{D}_{0}\left(x, y, b ; g_{\mathrm{y}}, g_{b}\right) \geq 0$. Based on this point, the revenue function can also be described as

$$
R(l, p, q)=\max _{x, y, b}\left\{p y-q b-l x: \overrightarrow{D_{0}}(x, y, b ; g) \geq 0\right\},
$$

If $(y, b) \in P(x)$, then

$$
\left(y+\beta g_{y}, b-\beta g_{b}\right)=\left\{\left(y+\vec{D}_{0}(x, y, b ; g) \cdot g_{y}, b-\vec{D}_{0}(x, y, b ; g) \cdot g_{b}\right) \in P(x)\right\},
$$

The Equation (6) means that the inefficiency of production unit $(y, b)$ can be eliminated along the direction $g$. In this sense, the directional distance function is also written as the following form.

$$
R(l, p, q) \geq(p,-q)\left(y+\overrightarrow{D_{0}}(x, y, b ; g) \cdot g_{y}, b-\overrightarrow{D_{0}}(x, y, b ; g) \cdot g_{b}\right)-l x,
$$

Or

$$
R(l, p, q) \geq(p y-q b-l x)+p \overrightarrow{D_{0}}(x, y, b ; g) \cdot g_{y}+q \overrightarrow{D_{0}}(x, y, b ; g) \cdot g_{b}
$$

The left side of inequality (8) is maximal revenue, while the right side equals actual revenue $(p y-q b-l x)$ plus the additional gain eliminating technical inefficiency. The additional gain consists of two components. One is a revenue increase generated by good outputs, i.e., $p \overrightarrow{D_{0}}(x, y, b ; g) \cdot g_{y}$. The other is generated due to bad output reductions, i.e., $q \vec{D}_{0}(x, y, b ; g) \cdot g_{b}$. If the decision-making unit moves along a direction vector to the frontier of $\mathrm{P}(\mathrm{x})$, the output allocation is efficient and then the inequality (12) will become the equality.

Rearranging inequality (8), the directional output distance function and the maximal revenue function are written as

$$
\overrightarrow{D_{0}}(x, y, b ; g) \leq \frac{R(l, p, q)-(p y-q b-l x)}{p g_{y}+q g_{b}},
$$

The directional output distance function given in Equation (1) can also be described as

$$
\vec{D}_{0}(x, y, b ; g)=\min _{p}\left\{\frac{R(l, p, q)-(p y-q b-l x)}{p g_{y}+q g_{b}}\right\},
$$


Applying the envelope theorem twice to Equation (10), we obtain the calculation of shadow prices

$$
\begin{gathered}
\nabla_{y} \vec{D}_{0}(x, y, b ; g)=-\frac{p}{p g_{y}+q g_{b}} \leq 0, \\
\nabla_{b} \vec{D}_{0}(x, y, b ; g)=\frac{q}{p g_{y}+q g_{b}} \geq 0,
\end{gathered}
$$

If the price of one desirable output, say the $m^{\text {th }}$ is known, the $j=1, \ldots, J$ nominal undesirable output prices can be recovered as

$$
q_{j}=-p_{m} \frac{\partial \vec{D}_{0}\left(x, y, b ; g_{y}, g_{b}\right) / \partial b_{j}}{\partial \vec{D}_{0}\left(x, y, b ; g_{y} g_{b}\right) / \partial y_{m}},
$$

The frontier shadow price is calculated by substituting the frontier values of $y$ and $b$ when evaluating the derivatives above. Accordingly, the prices of bad outputs can be calculated if one of the prices of good outputs is known.

\section{Empirical Analysis}

\subsection{Data and Variables}

The directional output distance function is estimated by using China provincial data (except Hong Kong and Macao of China) during 1997-2010 (In 1997, Chongqing became a municipality out of Sichuan province of China, so the initiative year in this paper is the year 1997). Tibet is excluded for its incomplete data, so the dataset in this paper covers 30 regions (22 provinces, 4 municipalities, and 4 autonomous regions). Specifically, each region uses energy consumption (tons of standard coal equivalent, TCE), capital stock ( $10^{8}$ Yuan, Yuan represents the monetary unit of China), and labor force $\left(10^{4}\right.$ person $)$ as inputs and produces one desirable output of GDP $\left(10^{8}\right.$ Yuan $)$ and one undesirable output of $\mathrm{CO}_{2}$ emissions ( $10^{4}$ ton). GDP, energy consumption, and labor are available in the China Statistical Yearbook and China Population Statistical Yearbook. All the monetary variables including GDP and capital stock have been converted into 1995 constant prices with GDP deflectors.

To the best of our knowledge, the data on capital stock cannot be obtained from any statistical yearbook or database directly. Following $\mathrm{Hu}$ and Kao [21] and Zhang [22], we apply the following perpetual inventory method to calculate the capital stock.

$$
K_{t}=K_{t-1}\left(1-\delta_{t}\right)+I_{t}
$$

where, $K_{t}$ is the gross capital stock in current year; $K_{t-1}$ is the gross capital stock in the previous year; $I_{t}$ is the gross fixed capital formation in the current year; $\delta$ represents the depreciation rate of capital stock and is set to $6 \%$ in accordance with the suggestions of many relevant studies such as $\mathrm{Wu}$ [23] and Zhang [22]. Capital stock of the base year $(t=1995)$ is from Sun [24].

China central and local governments have not promulgated the data of carbon emissions. This paper calculates China's $\mathrm{CO}_{2}$ emissions during the period of 1997-2010 In the light of the department method of IPCC, and the formula is as follows: 


$$
C O_{2}=\sum_{i=1}^{8} E_{i} \times F_{i},
$$

where $\mathrm{CO}_{2}$ is total carbon emissions of all types of energy consumption; $i$ indicates the types of carbonaceous fossil fuels, including coal, coke, crude oil, gasoline, kerosene, diesel, fuel oil, and natural gas in this paper; $E_{i}$ is the amount of consumption of fuel $i ; F_{i}$ is the carbon emission factor of fuel $i$. Equation (15) shows that the amount of $\mathrm{CO}_{2}$ emissions is highly related to the energy mix, which implies a low-carbon economy can only developed by reducing the consumption of carbonaceous fossil fuels.

In keeping with the unit of statistical data, energy unit is converted into tons of standard coal equivalent. The descriptive statistics for all data used are summarized in Table 1.

Table 1. Descriptive statistics (30 provinces, 14 years, 1997-2010).

\begin{tabular}{lccccc}
\hline Variable & Units & Mean & St. Dev. & Min. & Max. \\
\hline Output & & & & & \\
$\quad y=\mathrm{GDP}$ & $10^{8}$ Yuan & 5301.20 & 5139.41 & 195.68 & $30,219.33$ \\
$\quad 10^{4}$ ton & $22,666.88$ & $18,292.02$ & 659.03 & $111,400.50$ \\
\hline Input & & & & & \\
$\quad \mathrm{CO}_{2}$ emission & $10^{4}$ person & 1768.30 & 1157.93 & 171.94 & 6173.20 \\
$\quad x_{2}=$ Capor force & $10^{8}$ Yuan & 5372.94 & 4463.78 & 240.06 & $23,038.26$ \\
$x_{3}=$ Energy consumption & $10^{4} \mathrm{TCE}$ & 7816.45 & 5916.36 & 390.30 & $34,807.77$ \\
\hline
\end{tabular}

\subsection{The Shadow Price Estimation}

\subsubsection{The Quadratic Distance Function Form}

To calculate the shadow price of $\mathrm{CO}_{2}$, we estimate the directional output distance function via the parametric quadratic function form at first. In principle, the choice of direction vector is not important for the points on the production frontier. However, for the points which are interior of the frontier, the directional vector plays a role in determining shadow prices because different choices may result in different results. This paper chooses $g=(1,-1)$ as the directional vector, which not only simplifies the estimation of parameters, but satisfies the translation property mentioned above. The directional distance function can give the unit expansion of good outputs and the unit reduction of bad outputs in given inputs, which is also consistent with environmental regulations. One desirable output (y), one undesirable output $(b)$ and three inputs $(x)$ are selected to observe China's 30 provinces from 1997 to 2010 [25,26]. Therefore, the specific parametric quadratic function form is defined as

$$
\begin{aligned}
& \vec{D}_{0}(x, y, b ; 1,-1)=c_{0}+\sum_{n=1}^{3} d_{n} x_{n}+c_{1} y+c_{2} b+1 / 2 \sum_{n=1}^{3} \sum_{n=1}^{3} c_{n, n} x_{n} x_{n^{\prime}}+1 / 2 \alpha y^{2}+1 / 2 \beta b^{2} \\
& +\sum_{n=1}^{3} \delta_{n} x_{n} y+\sum_{n=1}^{3} \eta_{n} x_{n} b+\mu y b,
\end{aligned}
$$

According to the formula (13), the calculation of shadow prices is shown in Equation (17) 


$$
q=-p \frac{c_{2}+\beta b+\sum_{n=1}^{3} \eta_{n} x_{n}+\mu y}{c_{1}+\alpha y+\sum_{n=1}^{3} \delta_{n} x_{n}+\mu b},
$$

More narrowly, the parametric estimation of the quadratic distance function in Equation (16) is obtained by following Aigner and Chu [27]. We estimate the parameters of Equation (16) by solving the following minimization problem. The objective minimizes the sum of the deviations of the estimated distance functions from the frontier technology in each period.

$$
\min \sum_{\mathrm{t}=1}^{\mathrm{T}} \sum_{k=1}^{K}\left[\overrightarrow{D_{0}^{t}}\left(x_{k}^{t}, y_{k}^{t}, b_{k}^{t} ; 1,-1\right)-0\right]
$$

subject to

(i) $\overrightarrow{D_{0}^{t}}\left(x_{k}^{t}, y_{k}^{t}, b_{k}^{t} ; 1,-1\right) \geq 0, k=1, \ldots, K, t=1, \ldots, T$

(ii) $\partial \overrightarrow{D_{0}^{t}}\left(x_{k}^{t}, y_{k}^{t}, b_{k}^{t} ; 1,-1\right) / \partial y \leq 0, k=1, \ldots, K, t=1, \ldots, T$

(iii) $\partial \overrightarrow{D_{0}^{t}}\left(x_{k}^{t}, y_{k}^{t}, b_{k}^{t} ; 1,-1\right) / \partial b \geq 0, k=1, \ldots, K, t=1, \ldots, T$

(iv) $\mathrm{c}_{1}-c_{2}=-1, \alpha=\beta=\mu, \delta_{n}-\eta_{n}=0, \mathrm{n}=1,2,3$

(v) $c_{n, n}=c_{n^{\prime}, n}, \mathrm{n}=1,2,3$

The restriction given by (i) ensures feasibility of the output-input vector for each observation in each period. The inequality constraints in (ii) and (iii) impose the monotonicity, ensuring that the calculated shadow prices are of the correct sign. The parameter restrictions in (iv) are due to the translation property. The form of every restriction will change if a different directional vector is chosen [16]. Symmetry conditions are imposed in (v).

Considering the numerical size of outputs and inputs illustrated in Table 1, we encounter convergence problems in the deterministic model. To simplify the calculation process, we normalize the data by dividing each output and input by its mean value. The evaluation values of parameters are provided in Table 2. In view of parameter values, we should test whether the condition of null-jointness between desirable output and undesirable output is satisfied. Recall that $(y, b) \in P(x)$ if and only if $\vec{D}_{0}(x, y, b ; 1,-1) \geq 0$. Thus, the null-jointness can be tested by observing the values of $\vec{D}_{0}(x, y, 0 ; 1,-1)$ for $y>0$. If $\vec{D}_{0}(x, y, 0 ; 1,-1)<0,(y, 0) \notin P(x)$, then the property of null-jointness is feasible. Without undesirable outputs, there are no desirable outputs, and the two ones are jointly produced. The test results indicate that the null-jointness condition is satisfied for $89.3 \%$ of the observations (375/420), which is an acceptable result to guarantee the following calculation.

Table 2. Parameter values for the directional output distance function.

\begin{tabular}{cccccc}
\hline Parameter & Variable & Value & Parameter & Variable & Value \\
\hline $\mathrm{c}_{0}$ & 1 & -0.0295 & $\mathrm{c}_{31}$ & $1 / 2 \mathrm{x}_{3} \mathrm{x}_{1}$ & 0.5655 \\
$\mathrm{~d}_{1}$ & $\mathrm{x}_{1}$ & 0.7057 & $\mathrm{c}_{32}$ & $1 / 2 \mathrm{x}_{3} \mathrm{x}_{2}$ & 0.0025 \\
$\mathrm{~d}_{2}$ & $\mathrm{x}_{2}$ & 0.4018 & $\mathrm{c}_{33}$ & $1 / 2 \mathrm{x}_{3} \mathrm{x}_{3}$ & -0.1057 \\
$\mathrm{~d}_{3}$ & $\mathrm{x}_{3}$ & -0.2890 & $\alpha$ & $1 / 2 \mathrm{y}$ & -0.0219 \\
\hline
\end{tabular}


Table 2. Cont.

\begin{tabular}{cccccc}
\hline Parameter & Variable & Value & Parameter & Variable & Value \\
\hline $\mathrm{c}_{1}$ & $\mathrm{y}$ & -0.7287 & $\beta$ & $1 / 2 \mathrm{bb}$ & -0.0219 \\
$\mathrm{c}_{2}$ & $\mathrm{~b}$ & 0.2713 & $\delta_{1}$ & $\mathrm{x}_{1} \mathrm{y}$ & -0.1547 \\
$\mathrm{c}_{11}$ & $1 / 2 \mathrm{x}_{1} \mathrm{x}_{1}$ & -0.7193 & $\delta_{2}$ & $\mathrm{x}_{2} \mathrm{y}$ & 0.2946 \\
$\mathrm{c}_{12}$ & $1 / 2 \mathrm{x}_{1} \mathrm{x}_{2}$ & 0.2394 & $\delta_{3}$ & $\mathrm{x}_{3} \mathrm{y}$ & -0.1535 \\
$\mathrm{c}_{13}$ & $1 / 2 \mathrm{x}_{1} \mathrm{x}_{3}$ & 0.5655 & $\eta_{1}$ & $\mathrm{x}_{1} \mathrm{~b}$ & -0.1547 \\
$\mathrm{c}_{21}$ & $1 / 2 \mathrm{x}_{2} \mathrm{x}_{1}$ & 0.2394 & $\eta_{2}$ & $\mathrm{x}_{2} \mathrm{~b}$ & 0.2946 \\
$\mathrm{c}_{22}$ & $1 / 2 \mathrm{x}_{2} \mathrm{x}_{2}$ & -0.7523 & $\eta_{3}$ & $\mathrm{x}_{3} \mathrm{~b}$ & -0.1535 \\
$\mathrm{c}_{23}$ & $1 / 2 \mathrm{x}_{2} \mathrm{x}_{3}$ & 0.0025 & $\mu$ & $\mathrm{yb}$ & -0.0219 \\
\hline
\end{tabular}

\subsubsection{The Analysis of Results}

After obtaining the parameters of distance function, we can calculate the shadow prices according to Equation (17). Given the normalized data, we multiply by the ratio of the mean value of $y$ to the mean value of $b$ in order to inflate the ratio of the derivatives of the directional output distance function [12]. The resulting shadow prices are shown in Table 3. The national weighted average shadow prices (weighted by the proportion of provincial $\mathrm{CO}_{2}$ emissions) are showed in Figure 3. The total trend presents an "N-shape" curve, experiencing the initial phase of growth which is followed by a phase of deterioration and then a further increase. Before 2001, the shadow price increased and fluctuated between $450 \mathrm{Yuan} /$ ton and $650 \mathrm{Yuan} / \mathrm{ton}$, while it gradually decreased from 2002 to 2006. During the 11th Five-Year Economic Plan (2006-2010), China made efforts to build an energy-efficient and environmentally friendly society, which means stricter regulations and more costs to reduce emissions. From 2006, the weighted average shadow price started to recover and rapidly go up, and surpassed the former summit in 2007. Therefore, it is becoming more costly for the Chinese government to regulate $\mathrm{CO}_{2}$ emissions.

Table 3. Shadow prices of eight economic areas, 1997-2010 (unit: Yuan/ton).

\begin{tabular}{|c|c|c|c|c|c|c|c|c|c|c|c|c|c|c|c|c|}
\hline Areas & Provinces & 1997 & 1998 & 1999 & 2000 & 2001 & 2002 & 2003 & 2004 & 2005 & 2006 & 2007 & 2008 & 2009 & 2010 & average \\
\hline \multirow{6}{*}{ SE } & Shanghai & 1697 & 1959 & 2137 & 2206 & 2342 & 2525 & 2537 & 2641 & 2642 & 2750 & 2946 & 3169 & 3447 & 3612 & 2706 \\
\hline & Jiangsu & 1562 & 1565 & 1541 & 1375 & 1405 & 1454 & 1374 & 1255 & 1034 & 1037 & 1102 & 1204 & 1267 & 1233 & 1258 \\
\hline & Zhejiang & 877 & 1005 & 1014 & 982 & 1086 & 1006 & 999 & 1025 & 1012 & 1032 & 1095 & 1217 & 1340 & 1306 & 1112 \\
\hline & Hainan & 800 & 873 & 943 & 976 & 1017 & 1022 & 998 & 982 & 951 & 958 & 1008 & 1081 & 1141 & 1182 & 1050 \\
\hline & Fujian & 698 & 791 & 859 & 863 & 964 & 908 & 894 & 897 & 871 & 879 & 932 & 978 & 1006 & 1034 & 928 \\
\hline & Guangdong & 676 & 737 & 803 & 786 & 780 & 846 & 835 & 794 & 673 & 626 & 658 & 732 & 804 & 880 & 759 \\
\hline \multirow{4}{*}{$\mathrm{NC}$} & Beijing & 1254 & 1398 & 1550 & 1641 & 1719 & 1857 & 1911 & 1912 & 1863 & 1900 & 2028 & 2187 & 2305 & 2308 & 1881 \\
\hline & Hebei & 282 & 294 & 304 & 234 & 329 & 171 & 145 & 139 & 105 & 116 & 122 & 149 & 164 & 175 & 175 \\
\hline & Tianjin & 754 & 814 & 864 & 890 & 918 & 964 & 970 & 954 & 936 & 942 & 993 & 1037 & 1065 & 1050 & 959 \\
\hline & Shandong & 236 & 285 & 338 & 255 & 420 & 189 & 196 & 183 & 98 & 97 & 124 & 153 & 169 & 222 & 183 \\
\hline \multirow{4}{*}{ MY } & Anhui & 405 & 444 & 427 & 453 & 455 & 507 & 549 & 568 & 585 & 595 & 627 & 649 & 670 & 734 & 577 \\
\hline & Jiangxi & 488 & 541 & 577 & 594 & 614 & 579 & 546 & 538 & 521 & 525 & 561 & 594 & 610 & 637 & 571 \\
\hline & Hubei & 302 & 352 & 395 & 383 & 459 & 499 & 504 & 504 & 528 & 555 & 603 & 660 & 699 & 683 & 541 \\
\hline & Hunan & 232 & 257 & 389 & 412 & 385 & 382 & 359 & 320 & 254 & 296 & 308 & 328 & 341 & 304 & 319 \\
\hline
\end{tabular}


Table 3. Cont.

\begin{tabular}{|c|c|c|c|c|c|c|c|c|c|c|c|c|c|c|c|c|}
\hline Areas & Provinces & 1997 & 1998 & 1999 & 2000 & 2001 & 2002 & 2003 & 2004 & 2005 & 2006 & 2007 & 2008 & 2009 & 2010 & average \\
\hline \multirow{4}{*}{ NW } & Gansu & 424 & 438 & 449 & 483 & 520 & 531 & 521 & 518 & 504 & 513 & 551 & 596 & 644 & 651 & 540 \\
\hline & Ningxia & 568 & 621 & 676 & 720 & 751 & 752 & 688 & 674 & 658 & 664 & 707 & 757 & 800 & 824 & 726 \\
\hline & Qinghai & 605 & 658 & 690 & 735 & 765 & 779 & 768 & 747 & 713 & 719 & 763 & 813 & 865 & 895 & 773 \\
\hline & Xinjiang & 567 & 634 & 710 & 767 & 807 & 861 & 861 & 841 & 815 & 827 & 880 & 938 & 990 & 1029 & 862 \\
\hline \multirow{4}{*}{ MYR } & Shanxi & 72 & 85 & 113 & 133 & 38 & 11 & 30 & 35 & 36 & 36 & 37 & 82 & 136 & 155 & 69 \\
\hline & Henan & 411 & 367 & 370 & 380 & 358 & 371 & 332 & 246 & 234 & 211 & 201 & 199 & 208 & 218 & 261 \\
\hline & Shaanxi & 512 & 553 & 642 & 690 & 660 & 664 & 654 & 639 & 612 & 613 & 646 & 671 & 696 & 711 & 652 \\
\hline & Inner Mongolia & 352 & 412 & 373 & 444 & 416 & 433 & 375 & 305 & 243 & 189 & 204 & 180 & 166 & 168 & 245 \\
\hline \multirow{3}{*}{$\mathrm{NE}$} & Liaoning & 95 & 126 & 131 & 102 & 139 & 275 & 338 & 343 & 409 & 428 & 464 & 490 & 520 & 552 & 357 \\
\hline & Jilin & 221 & 303 & 354 & 414 & 445 & 457 & 462 & 494 & 553 & 567 & 610 & 643 & 689 & 731 & 532 \\
\hline & Heilongiiang & 127 & 168 & 191 & 249 & 297 & 376 & 413 & 446 & 475 & 504 & 560 & 597 & 652 & 710 & 450 \\
\hline \multirow{5}{*}{ SW } & Chongqing & 361 & 335 & 332 & 504 & 468 & 537 & 529 & 519 & 451 & 460 & 484 & 505 & 519 & 529 & 476 \\
\hline & Guangxi & 427 & 485 & 542 & 583 & 634 & 651 & 643 & 592 & 582 & 583 & 600 & 616 & 632 & 676 & 603 \\
\hline & Guizhou & 268 & 249 & 291 & 296 & 304 & 356 & 309 & 319 & 387 & 395 & 418 & 452 & 472 & 499 & 379 \\
\hline & Sichuan & 265 & 292 & 382 & 469 & 469 & 490 & 414 & 385 & 433 & 445 & 478 & 505 & 511 & 520 & 448 \\
\hline & Yunnan & 473 & 530 & 595 & 637 & 675 & 660 & 669 & 641 & 614 & 626 & 675 & 720 & 754 & 794 & 671 \\
\hline \multicolumn{2}{|c|}{ National average } & 331 & 344 & 400 & 463 & 475 & 509 & 471 & 457 & 481 & 489 & 519 & 549 & 566 & 594 & 475 \\
\hline
\end{tabular}

Figure 3. The national weighted average shadow prices.

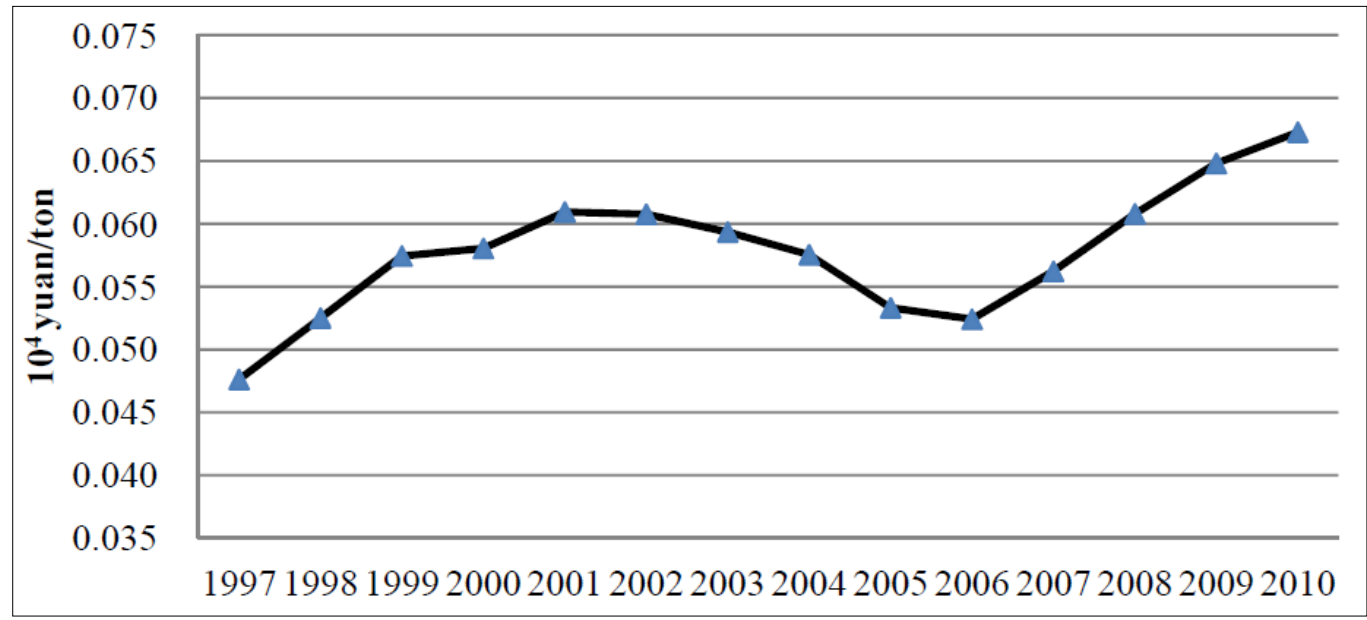

According to the Table 3, the shadow price varies significantly across provinces. In order to visually observe this difference, we class the shadow prices into three categories (high, middle, and low levels) according to the value of provincial average shadow price and map them in Figure 4. The high level means that the provincial shadow price is larger than 900 Yuan/ton, the middle level means that the provincial shadow price is between 500 and 900 Yuan/ton, and the low level represents that the provincial average shadow price is smaller than 500 Yuan/ton. In China, economic development levels are markedly different across regions. Figure 4 intuitively indicates that most regions with high economic development are accompanied by a high cost of carbon emissions reduction. Generally, the provinces with high economic development locate in the south-east coastal region (SE). Except Guangdong province, the shadow prices of the other provinces in SE region are higher than 1000 Yuan/ton. Especially, Shanghai, as the largest and most developed city of China, has 
the highest shadow price of 2706 Yuan/ton. So the abatement cost of SE region with high economic development is the highest in China. The provinces with low economic development levels generally locate in the northeastern areas (NE), the southwestern areas (SW), and the areas in the Middle Yellow River (MYR). The shadow prices of most provinces in these three regions are less than $500 \mathrm{Yuan} / \mathrm{ton}$, especially Shanxi province's shadow price is the lowest, only 69 Yuan/ton. However, the shadow prices of Shaanxi, Jilin, Guangxi, and Yunnan are lightly higher than 500 Yuan/ton. According to the administrative district of China's government, there are another three regions, that is, the northern coastal area (NC), the Middle Yangtze area (MY), and the northwestern area (NW). The shadow prices of most provinces in those three regions are in the middle levels, between 500 and $900 \mathrm{Yuan} / \mathrm{ton}$. It is worth noting that Beijing and Tianjin locate in the NC region, but their shadow prices are very high since these two municipalities feature both high economic development levels and high urbanization rates. In addition, the economic development of NW region is relatively low, but their shadow prices are in the middle levels (between 500 and 900 Yuan/ton). NW area features low technology levels and production inefficiency, and the economic development in NW area mainly depends on heavy industry, especially the energy industry. Under current conditions, the provinces in NW area have to confront with bigger economic losses to implement strategies to cut emissions.

Figure 4. The weighted average shadow prices of all provinces.

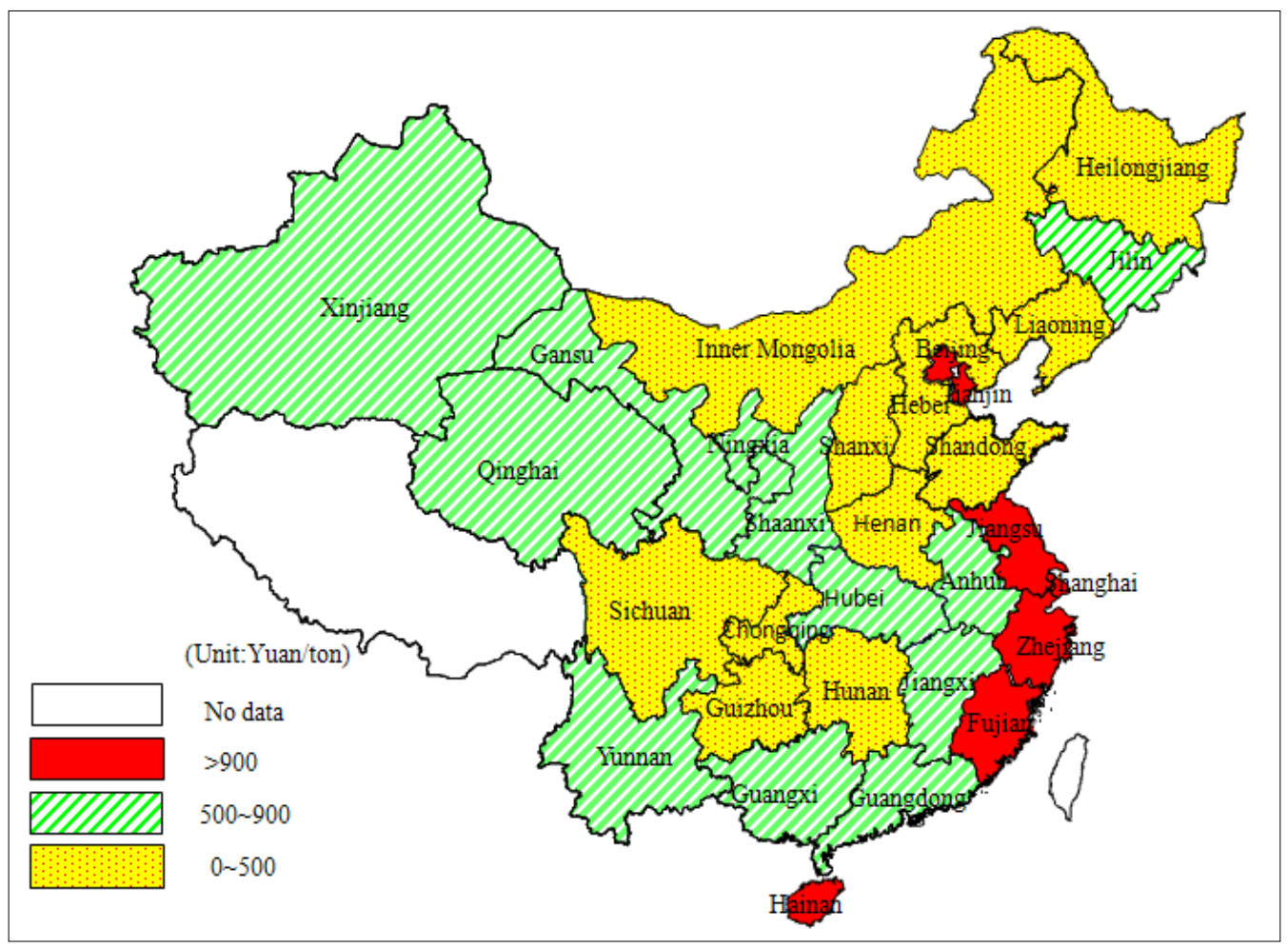

Generally, the cost of carbon emissions reduction is higher than that of previous studies on China's carbon emissions. Choi found the average shadow price of $\$ 7.2 /$ ton for China's 30 provinces during 2001-2010 [17]. Wei argued that the average marginal abatement cost of carbon dioxide emissions was 114.1 Yuan/ton during the period 1995-2007, while this paper derived a national average abatement cost of 475 Yuan/ton during the period 1997-2010 [28]. However, this does not mean our results contradict these studies. Both the dissimilarities in data and methods, especially the specification of the 
distance function, may lead to different results. What we should do is to provide feasible policy implications in emissions reductions by comparing the differences of shadow prices in various regions of China.

In order to further investigate the relationship between shadow prices of $\mathrm{CO}_{2}$ emissions and regional economic growth, we conduct an OLS regression:

$$
S P_{i}=\alpha_{i}+\alpha_{2} G D P P C_{i}+\alpha_{3} G D P P C_{i}^{2}+\alpha_{4} G D P P C_{i}^{3}+\varepsilon_{i}
$$

where $S P$ means the shadow price; GDPPC is GDP per capita; $\varepsilon$ is the disturbance term; $i$ is province index.

We employ the fixed effects model of panel data, and the results are shown in Table 4. The goodness-of-fit $\left(R^{2}=95.5 \%\right)$ and parameters testing results ( $p$-values $\left.\leq 0.01\right)$ show good performances. That means regression coefficients have significant difference at the $1 \%$ level. The estimation results indicate a positive sign for GDPPC coupled with a negative sign for its quadratic term and a positive sign for its cubic term. The curve illustrated in Figure 5 vividly shows how the shadow price of $\mathrm{CO}_{2}$ emissions changes with increasing GDP per capita (The " $\mathrm{x}$ " and " $y$ " axes are GDP per capita and shadow prices, respectively). Obviously, the shadow price increases with the economic growth. It is worth noting that an inflection point (GDP per capita $=18.1$ thousand Yuan) exists in Figure 5, that is, the increase rate of the shadow price gradually becomes small when the GDP per capita is less than 18.1 thousand Yuan, while it increasingly becomes large when the GDP per capita surpasses 18.1 thousand Yuan. This change trend implies that the carbon emissions abatement cost of China would be very expensive with the rapid economic growth.

Table 4. The estimation results of OLS.

\begin{tabular}{ccccc}
\hline Variable & Coefficient & Std. Error & T-Statistic & $\boldsymbol{p}$-value \\
\hline GDPPC & 0.022561 & 0.005073 & 4.446912 & 0.0000 \\
GDPPC $^{2}$ & -0.009277 & 0.002309 & -4.016974 & 0.0001 \\
GDPPC $^{3}$ & 0.001708 & 0.000292 & 5.848056 & 0.0000 \\
\hline
\end{tabular}

Figure 5. The relationship between the shadow price and GDP per capita.

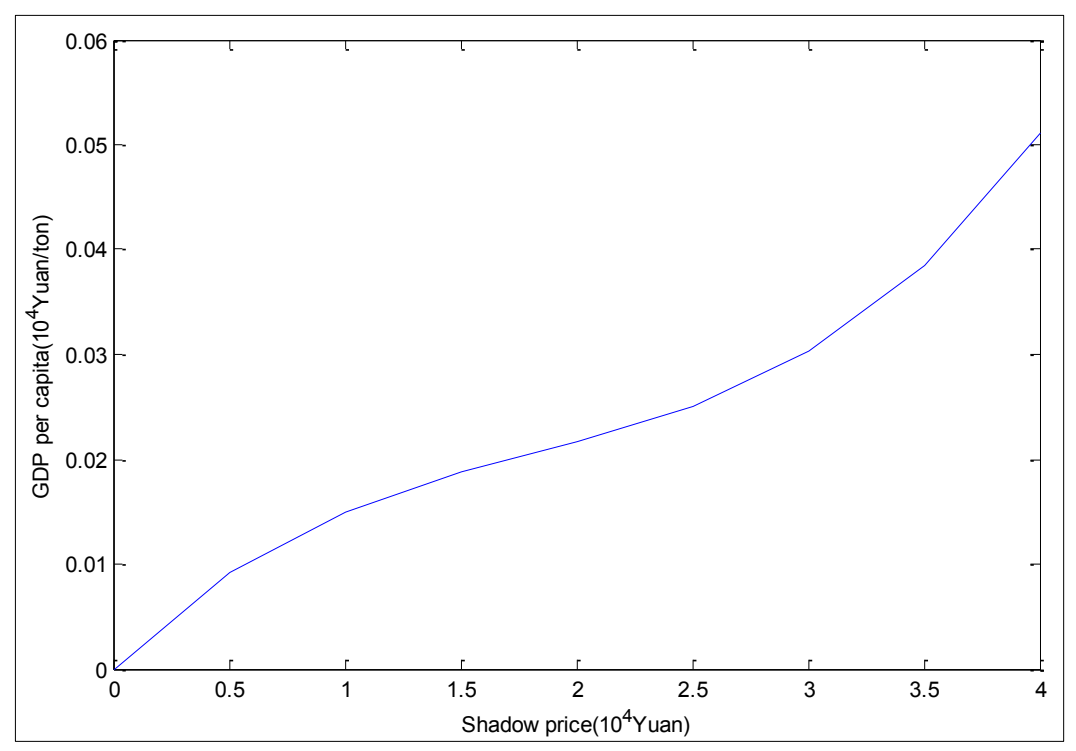




\subsection{The Policy Implications for China}

China has experienced rapid economic growth and social development in the past three decades. Although per capita carbon emissions of China are very low, China has been the biggest carbon emitter owing to the huge population size and rapid economic growth. Some studies argued that the carbon emissions reduction potential is large [29]. However, the empirical results of this paper indicate that the cost of carbon emissions abatement is very high and increases with time, which means it is very expensive for China to take green production technology. Globally, the developed countries should help developing counties to improve their production technology and efficiency since climate change mitigation is our common responsibility.

Nationally, since the shadow price varies significantly across regions, China should stick to the principle of "common but differentiated responsibilities" to reduce carbon emissions since cost of carbon emissions reduction varies significantly across provinces. Levying a non-uniform carbon tax across regions in China and introducing cap and carbon emissions trade may be the most possible alternatives to carbon emissions reduction, which are proved to be effective measures to carbon emissions abatement in some countries [30]. Those measures inevitably increase the price levels of production and service, which can promote public to form a low-carbon life pattern. Moreover, clean coal technique may be an inevitable choice for China since the coal is the dominant primary energy.

Regionally, the west low income provinces with rich coal should improve the clean coal technology since the coal is the dominant primary energy, and the east high income provinces should provide technology and fund to improve the production of west provinces since the west exports a large amount of energy to the east. In addition, promoting regional adaptive clean energy is an effective way to carbon emissions reduction: (a) The Chinese government should develop wind power and solar energy in some under-developed remote regions because they themselves possess abundant solar and wind energy resources, such as Shaanxi, Inner Mongolia, Xinjiang, Ningxia, and Qinghai provinces. (b) China should promote the applications of new energy vehicles and solar roofs vigorously, especially in cities of higher economic development since these regions with high economic development levels can afford the high popularization costs of new energy projects. Actually, China has implemented the promotion policy of "Ten Cities and Thousand Units" for new energy vehicles since 2009, which aims to accelerate the development of new energy vehicles through the national subsidy support. Thirteen pilot cities, such as Beijing, Shanghai, Chongqing, and Kunming, have been chosen as the first demonstration ones for this policy. Meanwhile, the Chinese government has launched a solar rooftop program, especially "The Plan to build ten thousand solar roofs in Shanghai". In the future, ten thousand solar roofs will be covered by the solar power systems, which can produce at least 430 million $\mathrm{kWh}$ of power per year. However, the new energy vehicles and solar roofs developed slowly. (c) Agriculture economy is still the basic pillar in China. Some regions rich in agricultural resources should develop biomass energy with great efforts, such as provinces of Jiangsu, Shandong, Heilongjiang, Henan, and so on. (d) As Heinonen and Junnila indicate, the level of carbon consumption is determined by income level, and carbon consumption is positively related to the income level [31]. Therefore, the low-carbon life style in regions with high income level is very important to carbon emissions reduction. 


\section{Conclusions}

This paper employs the quadratic directional output distance function to estimate the shadow price of China's provincial $\mathrm{CO}_{2}$ emissions. To dig into the differences of shadow price at the provincial level over time, we choose a sample of 30 provinces during the period of 1997-2010. The empirical results indicate the national weighted average shadow prices present an "N-shape" curve, experiencing the initial phase of growth followed by a phase of deterioration and then a further increase. Meanwhile, the cost of carbon emissions reduction varies significantly across provinces. The economically developed regions, i.e., Shanghai, Beijing, Jiangsu, Zhejiang, and Fujian will endure much more cost to additional $\mathrm{CO}_{2}$ emissions reduction. While some regions with low economic development levels (for example, Shanxi, Guizhou, Sichuan, Inner Mongolia and so on) will spend lower cost to $\mathrm{CO}_{2}$ emissions reduction. We conduct an OLS regression and find a positive relation between the shadow price and the economic development levels. In addition, an inflection point exists in the relation curve between the shadow price and GDP per capita, that is, the increase rate of the shadow price gradually becomes small when the GDP per capita is less than 18.1 thousand Yuan while it increasingly becomes large when the GDP per capita is greater than 18.1 thousand Yuan. The above results imply that the carbon emissions cost would be very high for China, and the green production technology is very expensive for China. Therefore, the international corporation and the technical support from developed counties are very important for China.

The empirical results indicate that the carbon emissions abatement cost markedly varies across regions in China. Generally, the shadow price of regions with high economic development level is significantly larger than that of regions with low economic development level. In addition, the economic development mechanism differentiates across regions in China. Therefore, China should uphold the principal of "common but differentiated responsibilities" and take regional adaptive policies to promote the carbon emissions reduction.

There are several additional avenues of future exploration in estimating the shadow prices of undesirable outputs. The shadow price model developed in this study could also be applied to the analysis of other undesirable outputs in the production process, such as $\mathrm{SO}_{2}$ emissions and industrial wastewater. However, one of the major missing points in this work is that the factors of technology and efficiency improvement is not accounted, and if these two factors are imbedded in the directional output distance function, the relationship between the shadow price and GDP per capita main presents a different situation, and this is the mainly research direction of our future research. Besides, because of inherent disadvantages of methods, future study will also combine the parametric and nonparametric methods, which would yield more valuable suggestions.

\section{Acknowledgments}

The authors would like to thank the anonymous referees and the editor of this journal. The authors gratefully acknowledge the financial support by the National Natural Science Foundation of China (Grant no. 71173075 and 71373077), Beijing Natural Science Foundation of China (Grant no. 9142016), Beijing Planning Project of Philosophy and Social Science (Grant no. 13JGB054), Ministry of Education Doctoral Foundation of China (Grant no. 20110036120013), Program for New Century 
Excellent Talents in University (NCET-12-0850), the China Chamber of International Commerce Business trade associations Business Information Research "Twelfth Five Year" Plan Project (CIECT-C1406) and the Fundamental Research Funds of the Central Universities of China.

\section{Author Contributions}

Jianjun Wang conceived and designed the study, Li Li completed the papers in English and gave many good research advices. Fan Zhang and Qiannan Xu collected and analyzed the data.

\section{Conflicts of Interest}

The authors declare no conflict of interest.

\section{References}

1. Statistical Review of World Energy 2013. Available online: www.bp.com/content/dam/ bp/pdf/statistical-review/statistical_review_of_world_energy_2013.pdf (accessed on 19 March 2014).

2. Gollop, F.M.; Roberts, M.J. Cost-minimizing regulation of sulfur emissions: Regional gains in electric power. Rev. Econ. Stat. 1985, 67, 81-90.

3. Shephard, R.W. Theory of Cost and Production Functions; Princeton University Press: Princeton, NJ, USA, 1970.

4. Lee, J.D.; Park, J.B.; Kim, T.Y. Estimation of the shadow prices of pollutants with production/environment inefficiency taken into account: A nonparametric directional distance function approach. J. Environ. Manag. 2002, 64, 365-375.

5. Kaneko, S.; Fujii, H.; Sawazu, N.; Fujikura, R. Financial allocation strategy for the regional pollution abatement cost of reducing sulfur dioxide emissions in the thermal power sector in China. Energ. Pol. 2010, 38, 2131-2141.

6. Färe R.; Grosskopf, S.; Lovell, C.A.K.; Yaisawarng, S. Derivation of shadow prices for undesirable outputs: a distance function approach. Rev. Econ. Stat. 1993, 75, 374-380.

7. Lee, M. The shadow price of substitutable sulfur in the US electric power plant: A distance function approach. J. Environ. Manag. 2005, 77, 104-110.

8. Hu, J.L.; L, Y.; Chiu, Y.H.; K, T.Y. Shadow prices of $\mathrm{SO}_{2}$ abatements for regions in China. Agr. Resour. Econ. 2008, 5, 59-78.

9. Hailu, A. Pollution abatement and productivity performance of regional Canadian pulp and paper industries. J. Forest Econ. 2003, 9, 5-25.

10. Murty, M.N.; Kumar, S.; Paul, M. Environmental regulation, productive efficiency and cost of pollution abatement: A case study of the sugar industry in India. J. Environ. Manag. 2006, 79, 1-9.

11. Chambers, R.G.; Chung, Y.; Färe, R. Profit, directional distance functions, and Nerlovian efficiency. J. Optim. Theor. Appl. 1998, 98, 351-364.

12. Färe, R.; Grosskopf, S.; Noh, D.W.; Weber, W. Characteristics of a polluting technology: Theory and practice. J. Econ. 2005, 126, 469-492.

13. Färe, R.; Grosskopf, S.; Weber, W.L. Shadow prices and pollution costs in U.S. agriculture. Ecol. Econ. 2006, 56, 89-103. 
14. Vardanyan, M.; Noh, D.W. Approximating pollution abatement costs via alternative specifications of a multi-output production technology: A case of the US electric utility industry. J. Environ. Manag. 2006, 80, 177-190.

15. Matsushita, K.; Yamane, F. Pollution from the electric power sector in Japan and efficient pollution reduction. Energ. Econ. 2012, 34, 1124-1130.

16. Wang, Q.W.; Cui, Q.J.; Zhou, D.Q.; Wang, S.S. Marginal abatement costs of carbon dioxide in China: A nonparametric analysis. Energ. Procedia 2011, 5, 2316-2320.

17. Choi, Y.; Zhang, N.; Zhou, P. Efficiency and abatement costs of energy-related $\mathrm{CO}_{2}$ emissions in China: A slacks-based efficiency measure. Appl. Energ. 2012, 98,198-208.

18. Yuan, P.; Liang W.B.; Cheng, S. The marginal abatement costs of $\mathrm{CO}_{2}$ in Chinese industrial sectors. Energy Procedia 2011, 14, 1792-1797.

19. Lee, M.; Zhang, N. Technical efficiency, shadow price of carbon dioxide emissions, and substitutability for energy in the Chinese manufacturing industries. Energ. Econ. 2012, 34, 1492-1497.

20. Kwon, O.S.; Yun, W.C. Estimation of the marginal abatement costs of airborne pollutants in Korea's power generation sector. Energ. Econ. 1999, 21,547-560.

21. Hu, J.L.; Kao, C.H. Efficient energy-saving targets for APEC economies. Energ. Pol. 2007, 35, 373-382.

22. Zhang, X.P.; Tan, Y.K.; Tan, Q.L.; Yuan, J.H. Decomposition of aggregate $\mathrm{CO}_{2}$ emissions within a joint production framework. Energ. Econ. 2012, 34, 1088-1097.

23. Wu, Y. Openness, productivity and growth in the APEC economies. Empir. Econ. 2004, 29, 593-604.

24. Sun, H.; Zhi, D.L. Estimate of capital stock of provinces in China and the typical fact from 1978 to 2008. J. Financ. Econ. 2010, 25, 107-115.

25. National Bureau of Statistics of China. China Energy Statistical Yearbook; China Statistics Press: Beijing, China, 2012. (In Chinese)

26. National Bureau of Statistics of China (NBSC). China Statistical Yearbook 2013. Available online: http://www.stats.gov.cn/tjsj/ndsj (accessed on 7 January 2014). (In Chinese)

27. Aigner, D.J.; Chu, S.F. On estimating the industry production function. Am. Econ. Rev. 1968, 58, 826-839.

28. Wei, C.; Ni, J.; Du, L. Regional allocation of carbon dioxide abatement in China. China Econ. Rev. 2012, 23, 552-565.

29. Du, L.; Wei, C.; Cai, S. Economic development and carbon dioxide emissions in China: Provincial panel data analysis. China Econ. Rev. 2012, 23, 371-384.

30. Wei, Z.X.; Li, W.J.; Wang, T. The impacts and countermeasures of levying carbon tax in China under low-carbon economy. Energy Procedia 2011, 5, 1968-1973.

31. Heinonen, J.; Junnila, S. A carbon consumption comparison of rural and urban lifestyles. Sustainability 2011, 3, 1234-1249.

(C) 2014 by the authors; licensee MDPI, Basel, Switzerland. This article is an open access article distributed under the terms and conditions of the Creative Commons Attribution license (http://creativecommons.org/licenses/by/3.0/). 